Article

\title{
Enhanced Visible Light Photodegradation of Microplastic Fragments with Plasmonic Platinum/Zinc Oxide Nanorod Photocatalysts
}

\author{
Tajkia Syeed Tofa ${ }^{1,2}\left(\mathbb{D}\right.$, Fei Ye $^{3}\left(\mathbb{D}\right.$, Karthik Laxman Kunjali ${ }^{3(\mathbb{D}}$ and Joydeep Dutta ${ }^{3, *(\mathbb{C}}$ \\ 1 Department of Sustainable Development, Environmental Science and Engineering (SEED), School of \\ Architecture and Built Environment, KTH Royal Institute of Technology, 10044 Stockholm, Sweden; \\ tstofa@kth.se \\ 2 Department of Civil and Environmental Engineering (CEE), Islamic University of Technology, Gazipur 1704, \\ Dhaka, Bangladesh \\ 3 Functional Materials, Department of Applied Physics, School of Engineering Sciences, KTH Royal Institute \\ of Technology, 16440 Kista, Stockholm, Sweden; feiy@kth.se (F.Y.); laxman@kth.se (K.L.K.) \\ * Correspondence: joydeep@kth.se; Tel.: +46-8-7908142
}

Received: 14 September 2019; Accepted: 26 September 2019; Published: 28 September 2019

\begin{abstract}
Microplastics are persistent anthropogenic pollutants which have become a global concern owing to their widespread existence and unfamiliar threats to the environment and living organisms. This study demonstrates the degradation of fragmented microplastics particularly low-density polyethylene (LDPE) film in water, through visible light-induced plasmonic photocatalysts comprising of platinum nanoparticles deposited on zinc oxide $(\mathrm{ZnO})$ nanorods ( $\mathrm{ZnO}-\mathrm{Pt}$ ). The $\mathrm{ZnO}-\mathrm{Pt}$ nanocomposite photocatalysts were observed to have better degradation kinetics for a model organic dye (methylene blue) compared to bare $\mathrm{ZnO}$ nanorods, attributed to the plasmonic effects leading to better interfacial exciton separation and improved hydroxyl radical activity along with a $78 \%$ increase in visible light absorption. These demonstrations of the plasmonically enhanced photocatalyst enabled it to effectively degrade microplastic fragments as confirmed following the changes in carbonyl and vinyl indices in infrared absorption. In addition, visual proof of physical surface damage of the LDPE film establishes the efficacy of using plasmonically enhanced nanocomposite photocatalytic materials to tackle the microplastic menace using just sunlight for a clean and green approach towards mitigation of microplastics in the ecosystem.
\end{abstract}

Keywords: microplastics; visible light photodegradation; $\mathrm{ZnO}$ nanorod; platinum nanoparticle; nanocomposite; LDPE film

\section{Introduction}

Plastic based commodities are among the most widely used items in the modern world. The term 'microplastic (MP)' refers to any fragmented plastic material with sizes less than $5 \mathrm{~mm}$ or lower. They can be broadly categorized into primary and secondary microplastics that are mostly used in personal care products, cosmetics, medicines, textiles or disintegrate from larger plastic products $[1,2]$. The actual amount of microplastics in the ecosystem is beyond quantification, due to its infinitesimal size, light-weight, persistent characteristics, and widespread occurrence in the environmental system. It has been estimated that between $0.48-1.27$ million/annum of plastic debris enters the ocean from different sources [3], with the major sources being: Effluents discharged from wastewater treatment plants (WWTPs), surface runoff from contaminated landscape or disposal lands, and beach littering $[4,5]$. 
Removal of microplastics from water or wastewater is difficult, due to the intrinsic physical and chemical characteristics. Few studies suggest advanced treatment technologies like membrane bioreactor, bacterial oxidation, retrofilteration that could be suitable for removing microplastics from aqueous media, but can be time-consuming and expensive often with high energy requirements [6,7]. Other available options are removal by physical or mechanical means or degradation by thermal, chemical or catalytic processes [8,9]. Certain type of chemicals, such as persulfate salts, have been widely applied to produce reactive oxygen species (ROS) and hydroxyl radical for advanced oxidation. Previous studies showed that transition metals (e.g., $\mathrm{Fe}, \mathrm{Co}, \mathrm{Mn}$ ) and their oxides are excellent activators for persulfate salts in producing sulfate radicals during catalytic process for organic/inorganic contaminants removal [10]. Recently, carbon nanomaterials emerged as metal-free alternatives and were applied for activation of persulfate salts in catalytic degradation of microplastics [11]. On the other hand, photo-mediated catalytic degradation, one of the advanced oxidation processes (AOPs), has been shown to be an energy-efficient process to degrade microplastics in water wherein the typically nanostructured photocatalyst play an important role for expediting the degradation process by generating reactive species like hydroxyl $(\bullet \mathrm{OH})$ and superoxide $\left(\bullet \mathrm{O}_{2}^{-}\right)$radicals in the presence of light with appropriate energy. These species directly initiate the degradation process, which leads to polymeric chain breaking, branching, crosslinking and complete mineralization [12-14].

Nanoscale semiconductors, such as $\mathrm{TiO}_{2}, \mathrm{ZnO}$ and $\mathrm{ZnS}$, have been extensively studied in photocatalysis applications from water splitting to pollutant degradation. $\mathrm{TiO}_{2}$ nanomaterials have been reported on their capability to photocatalytically degrade microplastics, due to their high photocatalytic activity $[15,16]$. In comparison to other photocatalysts, nanostructured zinc oxide $(\mathrm{ZnO})$, a semiconductor with a band gap of $3.37 \mathrm{eV}$, has been used in water and wastewater treatments, due to its high redox potential, higher electron mobility at room temperature and better catalytic performance $[17,18]$. Hexagonal $\mathrm{ZnO}$ nanorods have a higher surface area and stability in comparison to spherical nanoparticles, leading to a more efficient photo-oxidation process [14]. For further improvement of photocatalytic activities of $\mathrm{ZnO}$, metals, nonmetals, and carbon materials can be deposited on $\mathrm{ZnO}$ to modify their optical characteristics and to improve electron-hole pair separation, which is essential for enhancing the photocatalytic process [19]. Studies have shown that by depositing platinum, a plasmonic metal, the overall photocatalytic efficiency can be improved, due to reduced electron-hole pair recombination and enhanced visible light absorption. Both these aspects are a consequence of surface plasmon resonance phenomenon, wherein a particular wavelength of electromagnetic spectra incident on metal nanostructures of platinum, gives rise to the resonance of interfacial conduction electrons, leading to enhanced absorption of light in such nanocomposite [18-23].

In this study, the photocatalytic activity of $\mathrm{ZnO}$ nanorods was modified by depositing platinum nanoparticles on the nanorod surface, and the photocatalytic performance of the nanocomposite was studied. Multiple characterization tools were applied to follow the effective degradation of low-density polyethylene (LDPE) films, which are the most widely found microplastic pollutant in water and wastewater systems $[2,6]$. 


\section{Results and Discussion}

\subsection{Morphology and Crystal Structure of Designed Photocatalysts}

The average diameter and length of synthesized $\mathrm{ZnO}$ nanorods and $\mathrm{ZnO}$ nanorods-supported platinum nanoparticles ( $\mathrm{ZnO}-\mathrm{Pt}$ ) were estimated to be $55 \mu \mathrm{m}$ and $960 \mu \mathrm{m}$ (same for both cases) respectively, in SEM images, as shown in Figure 1. The micrographs clearly indicate that there is a considerable increase in $\mathrm{ZnO}$ nanorod surface roughness and morphology after deposition of platinum nanoparticles. The weight percentage of $\mathrm{Zn}, \mathrm{O}$ and $\mathrm{Pt}$ in $\mathrm{ZnO}-\mathrm{Pt}$ samples were found to be $70.6 \%$, $23.9 \%, 5.4 \%$ respectively (see Figure S2 in Supplementary Materials).
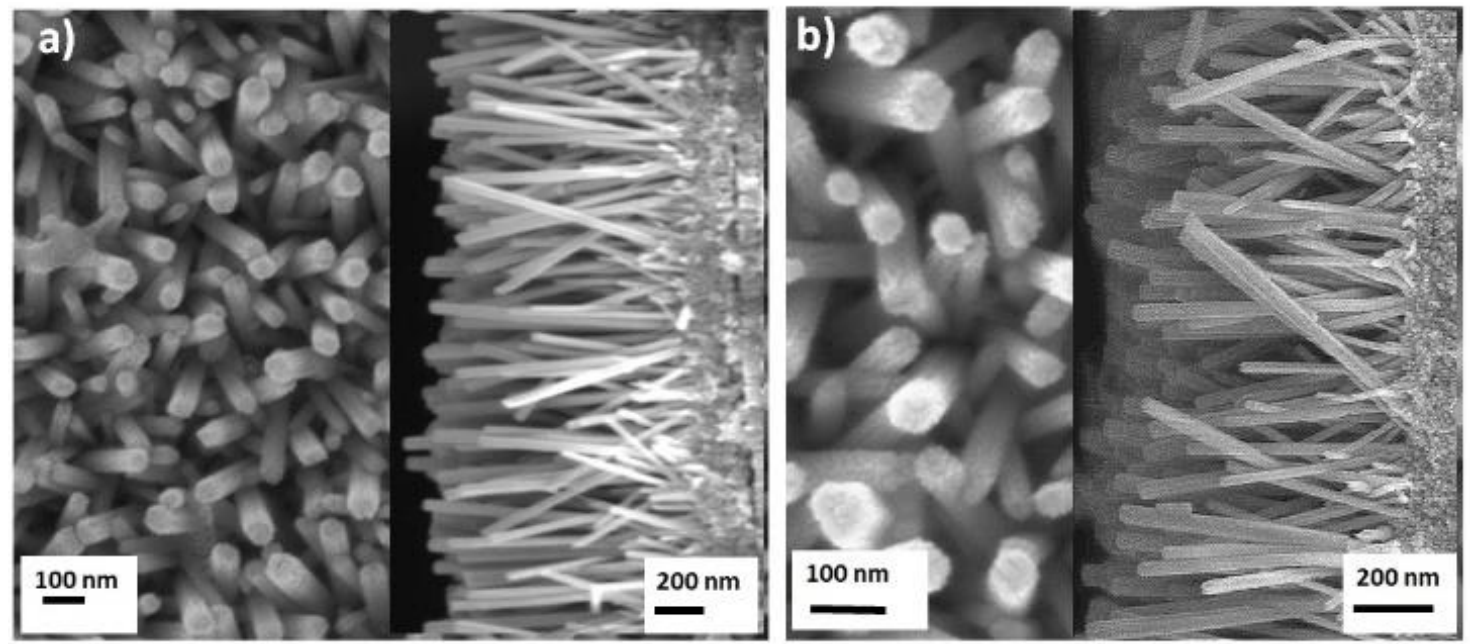

Figure 1. SEM images of (a) ZnO nanorods and (b) platinum nanoparticles-deposited of $\mathrm{ZnO}$ nanorods $(\mathrm{ZnO}-\mathrm{Pt})$. Top and cross-sectional views show the diameter and length of nanorods, respectively.

High resolution transmission electron microscope (HR-TEM) was also used to obtain a more detailed insight on morphology and crystal structure of deposited $\mathrm{Pt}$ nanoparticles on the $\mathrm{ZnO}-\mathrm{Pt}$ nanorods. Figure 2 indicates that the platinum nanoparticles were distributed homogenously on the $\mathrm{ZnO}$ nanorod surface as confirmed from their lattice spacing's of $2.30 \AA$ and $1.97 \AA$ (see Figure 2c), that respectively correspond to (111) and (200) planes of a face centered cubic crystal structure of platinum. The lattice spacing of $\mathrm{ZnO}$ nanorod as background in Figure $2 \mathrm{c}$ is about $2.60 \AA$, which corresponds to (002) plane of hexagonal wurtzite zinc oxide crystals. Figure $2 d$ shows the selected-area electron diffraction (SAED) pattern of $\mathrm{ZnO}-\mathrm{Pt}$ nanorods. The diffraction spots on rings can be indexed from (100), (101), (110) and (201) crystal planes of $\mathrm{ZnO}$, as well as from (111), (200) and (220) planes of platinum, labelled in Figure 2d. Thereafter, the hexagonal wurtzite crystal structure of $\mathrm{ZnO}$ and face-centered cubic structure of platinum are, thus, confirmed [24]. The average size of platinum nanoparticles is about $2.6 \mathrm{~nm}$ with a standard deviation $(\sigma)$ of $0.8 \mathrm{~nm}(\mathrm{n}=200)$. The size distribution of platinum nanoparticles is plotted in Figure 2e. 


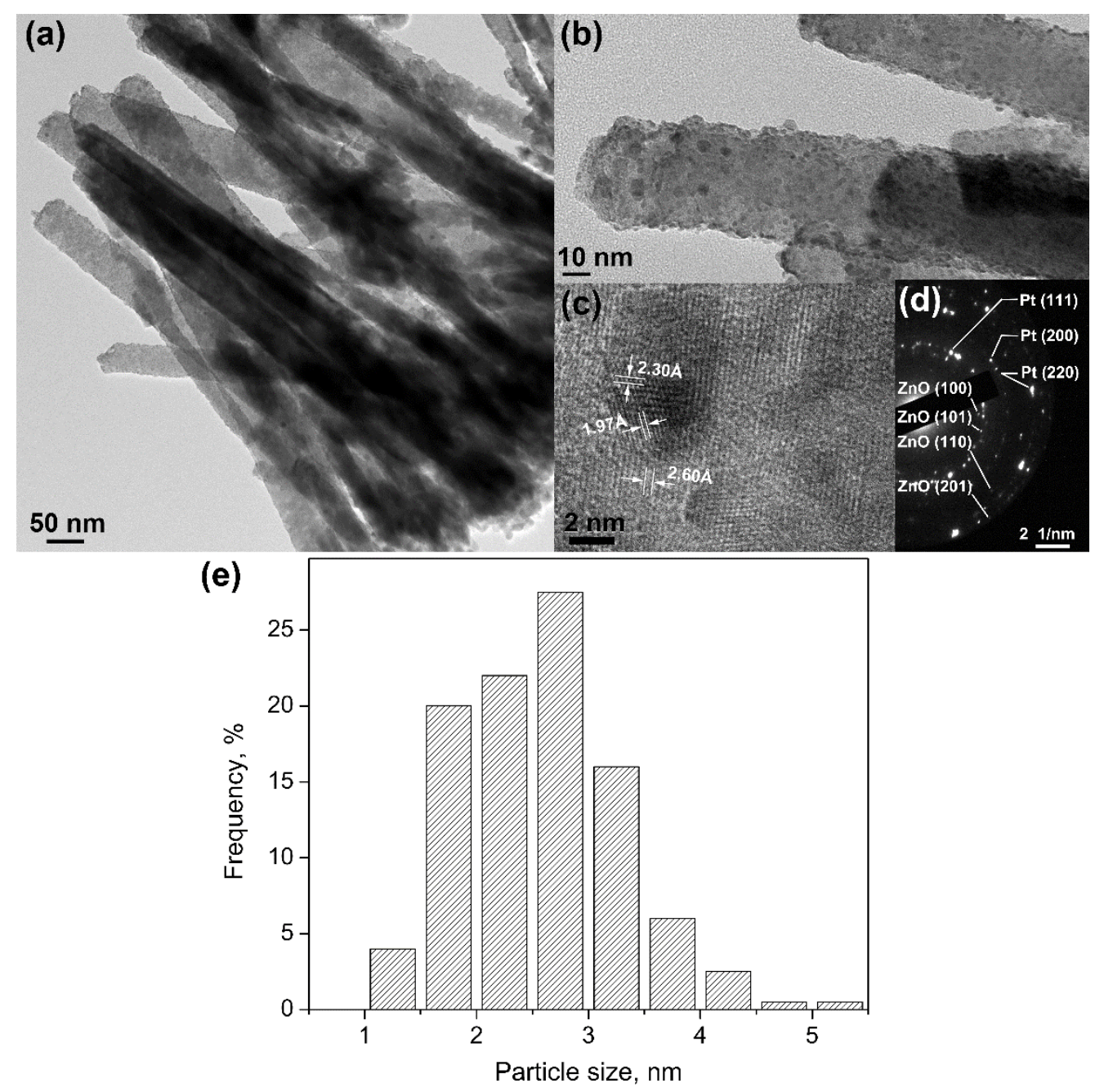

Figure 2. TEM images of platinum nanoparticles deposited on $\mathrm{ZnO}$ nanorods: (a,b) Uniformly deposited platinum nanoparticles on $\mathrm{ZnO}$ nanorods; (c) High resolution image showing the lattice spacing of platinum nanoparticles and $\mathrm{ZnO}$ nanorods, (d) SAED pattern of $\mathrm{ZnO}-\mathrm{Pt}$; and (e) particle size distribution of platinum nanoparticles grown on the surface of $\mathrm{ZnO}$ nanorods.

\subsection{Modification of Optical Properties of $\mathrm{ZnO} / \mathrm{Pt}$ Nanocomposite}

UV-VIS absorbance spectra of unmodified $\mathrm{ZnO}$ nanorods and $\mathrm{ZnO}$ nanorods loaded with platinum nanoparticles were recorded over 300 to $750 \mathrm{~nm}$. As can be observed from Figure 3, due to their inherent semiconductor properties, $\mathrm{ZnO}$ nanorods showed strong absorption in the UV region, but a weaker absorption in the visible region. However, upon deposition of platinum nanoparticles on the $\mathrm{ZnO}$ nanorods surface, a 78\% enhancement in the absorption in the visible region could be observed, which is attributed to the surface plasmon resonance effect of platinum nanoparticles at $385 \mathrm{~mm}$ [20]. 

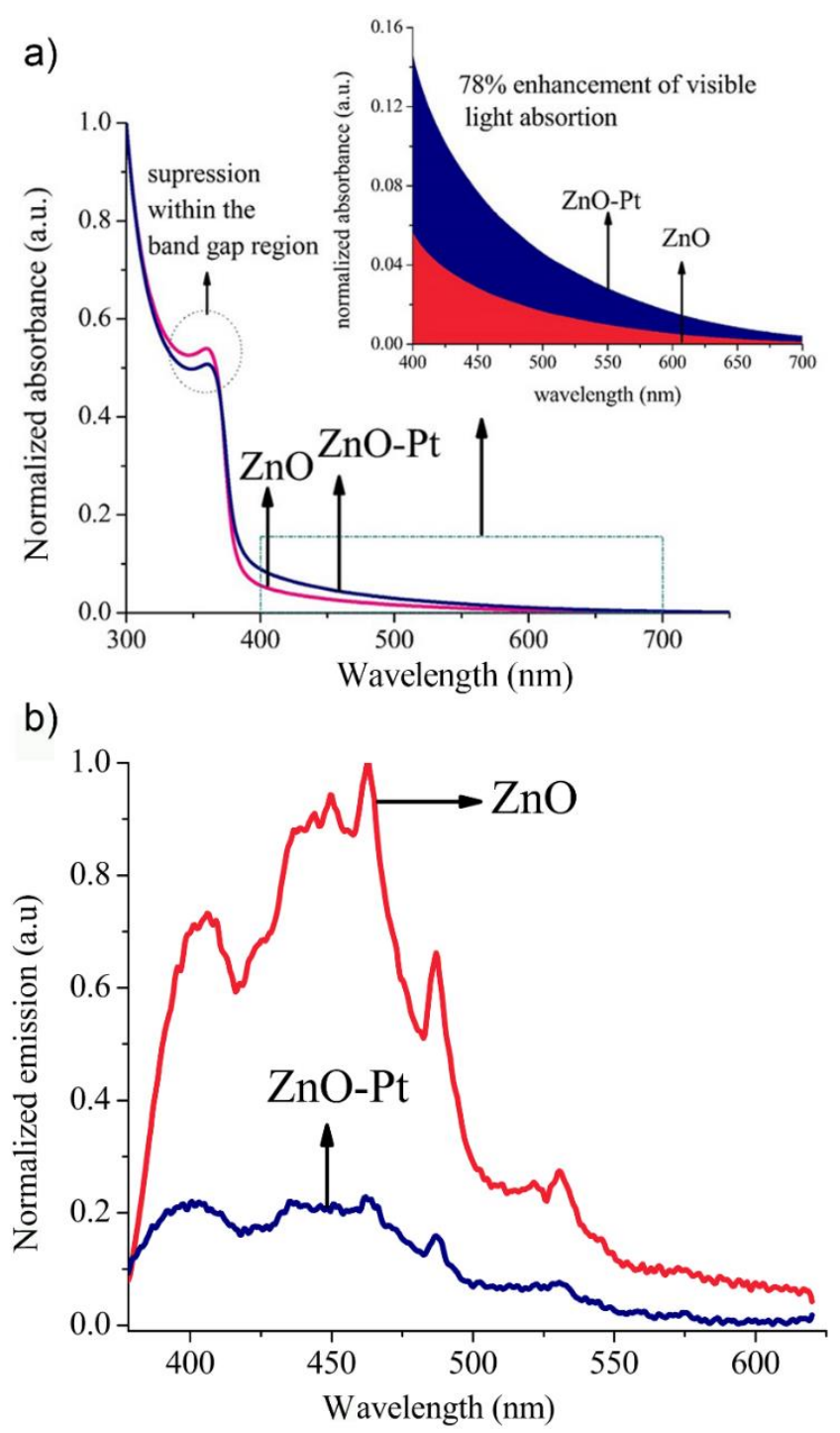

Figure 3. (a) UV-VIS adsorption spectra of $\mathrm{ZnO}$ nanorods and platinum nanoparticle-deposited $\mathrm{ZnO}$ nanorods. (b) Emission spectra of $\mathrm{ZnO}$ nanorods and $\mathrm{ZnO}-\mathrm{Pt}$ with $320 \mathrm{~nm}$ excitation. Reduction in the $\mathrm{PL}$ intensity for $\mathrm{ZnO}-\mathrm{Pt}$ indicates lower electron-hole recombination rate than that for $\mathrm{ZnO}$ nanorods.

Simultaneously, there was a reduction in the $\mathrm{ZnO}$ band-to-band excitation at $362 \mathrm{~nm}$ which could be a result of the increased defect density within the $\mathrm{ZnO}$ nanorod structure, due to UV-light exposure prior to platinum deposition (also indicated by the extended absorption tail in the visible region) and reduced light intensity incident on the surface of $\mathrm{ZnO}$ nanorods. Thus, both the phenomena contribute to the improvement in optical absorption in the visible region. Compared to as-grown $\mathrm{ZnO}$ nanorod samples, PL spectrum of $\mathrm{ZnO}-\mathrm{Pt}$ (Figure 3b) displays a considerable reduction in the radiative recombination of the photo-generated excitons. This is in accordance with the band positions and Fermi levels on either side of the $\mathrm{ZnO}-\mathrm{Pt}$ interface, where the work function of platinum $(-5.65 \mathrm{eV}$ w.r.t. vacuum) and electron affinity of $\mathrm{ZnO}(-4.5 \mathrm{eV}$ w.r.t. vacuum), along with the higher Fermi level of n-type $\mathrm{ZnO}$ gives rise to a Schottky junction with a barrier height of approximately $\varphi \mathrm{B}=1.15 \mathrm{eV}$. Therefore, an electric field will be built between $\mathrm{ZnO}$ and $\mathrm{Pt}$; and the direction of this electric field is from $\mathrm{ZnO}$ to Pt. Due to the relative position of conduction band of $\mathrm{ZnO}$ and Fermi level of platinum, the platinum nanoparticle coating will act as a sink for the photo-excited electrons in the interface with $\mathrm{ZnO}$, reducing the viability of radiative and non-radiative recombination processes for the photo mediated exciton pairs in $\mathrm{ZnO}$. This, in turn, will lead to a reduction in the PL intensity as observed 
from Figure $3 b$. However, this phenomenon leads to a higher degree of radical species to be formed in the presence of water, due to charge transfer reactions between water molecules and the individual excitons (electrons and holes), which can aid the photocatalytic degradation process [18,23,25-27].

\subsection{Photocatalytic Activity Test for $\mathrm{ZnO}$ and $\mathrm{ZnO}-\mathrm{Pt}$}

Experiments were carried out using methylene blue (MB) dye as a model organic contaminant to test the photocatalytic propensity of the $\mathrm{ZnO}$ and $\mathrm{ZnO}$-Pt catalysts. It is well documented that $\mathrm{MB}$ can undergo photolysis under visible light irradiation (without a catalyst), a phenomenon also observed in our experiments, as shown in Figure 4 [28,29]. With the inclusion of a $\mathrm{ZnO}$ nanorod catalyst in the process, a substantial enhancement in the photodegradation of methylene blue could be observed. This is expected as the photo generated electrons and holes (excitons) on the $\mathrm{ZnO}$ nanorods will react with the surrounding water to form radical species $\left(\bullet \mathrm{OH}, \bullet \mathrm{O}_{2}^{-}\right)$which can degrade MB $[18,30]$. The degradation phenomenon was further enhanced by almost $18 \%$ with the addition of platinum nanoparticles on the $\mathrm{ZnO}$ nanorods. This additional enhancement is activated by the improved charge separation, mediated by the favorable energy band alignment at the $\mathrm{ZnO}-\mathrm{Pt}$ interface as explained previously, along with additional electrons pumped into the $\mathrm{ZnO}$ nanorods from the platinum nanoparticles, due to the induced surface plasmon resonance $[19,27]$.

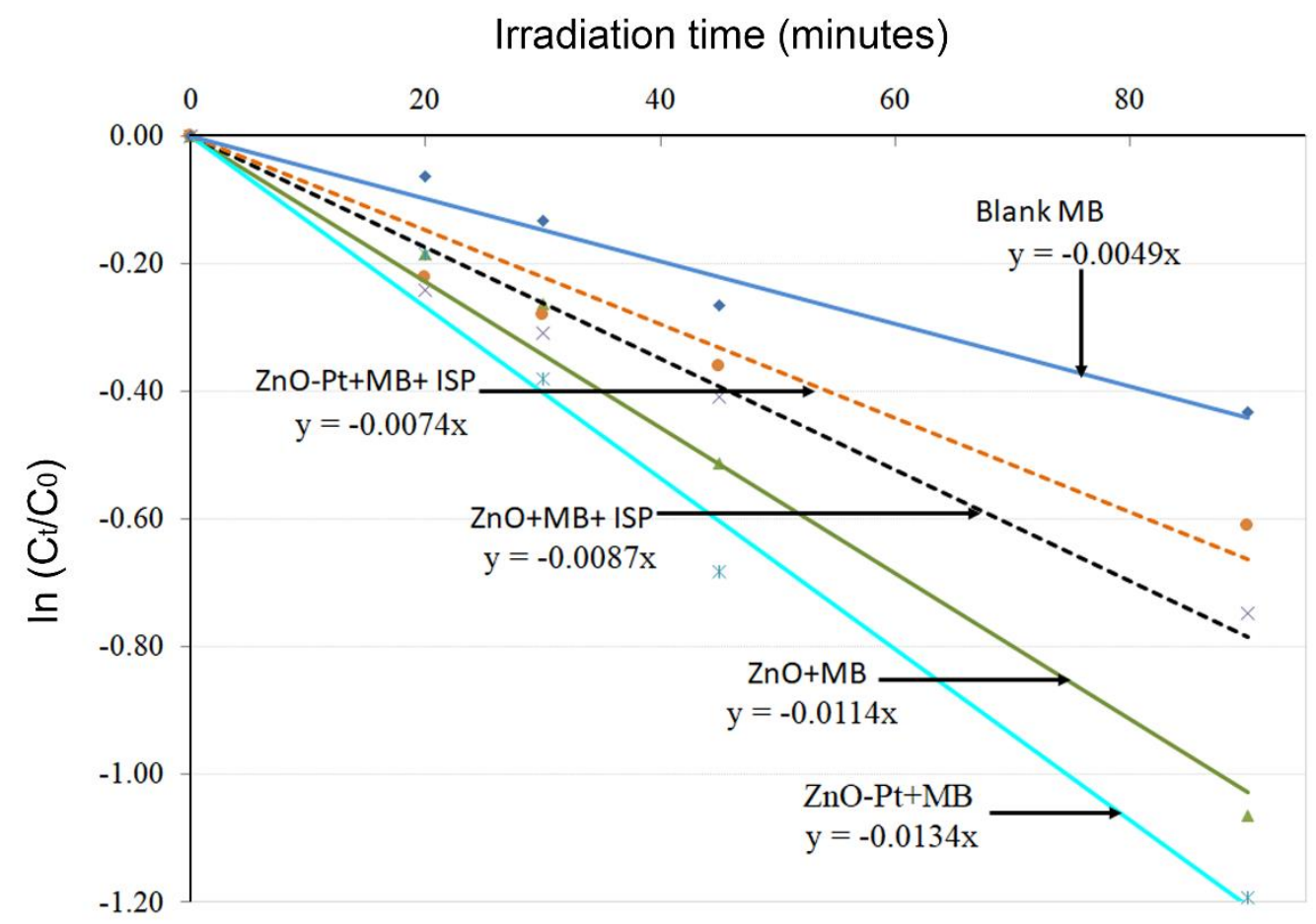

Figure 4. Photocatalytic activities of $\mathrm{ZnO}$ and $\mathrm{ZnO}-\mathrm{Pt}$ catalysts and the effect of $\bullet \mathrm{OH}$ scavengers on the degradation kinetics. (MB, methylene blue; ISP, isopropanol).

Further proof of the effect of a plasmonic nanoparticle coating was provided by experiments specifically carried out to identify the primary radical species $\left(\bullet \mathrm{OH}, \bullet \mathrm{O}_{2}^{-}\right)$taking part in the degradation process (Figure 4). Photocatalytic oxidation of methylene blue was carried out under visible light in the presence of isopropanol (ISP), which is a known hole scavenger. As observed from the reduction in degradation kinetics and efficiency in the presence of isopropanol for both $\mathrm{ZnO}$ and $\mathrm{ZnO}-\mathrm{Pt}$ photo-catalysts (Figure 4), it is clear that hydroxyl radicals are the primary species mediating the oxidation of MB. However, it is interesting to note that the reduction in MB oxidation is much more pronounced in the presence of $\mathrm{ZnO}-\mathrm{Pt}$ catalysts, suggesting that the plasmonic nanoparticle coating leads to increased hydroxyl radical generation (compared to unmodified $\mathrm{ZnO}$ nanorod samples), which in turn is an additional proof that the platinum coating improves the exciton separation efficiency. 
The above-mentioned process is pictorially depicted in Figure 5 to illustrate the band alignment at the $\mathrm{ZnO}-\mathrm{Pt}$ interface scheme, where the platinum nanoparticles act as electron sinks to arrest/reduce the exciton recombination process to aid in the photocatalytic reactions [20,31,32].

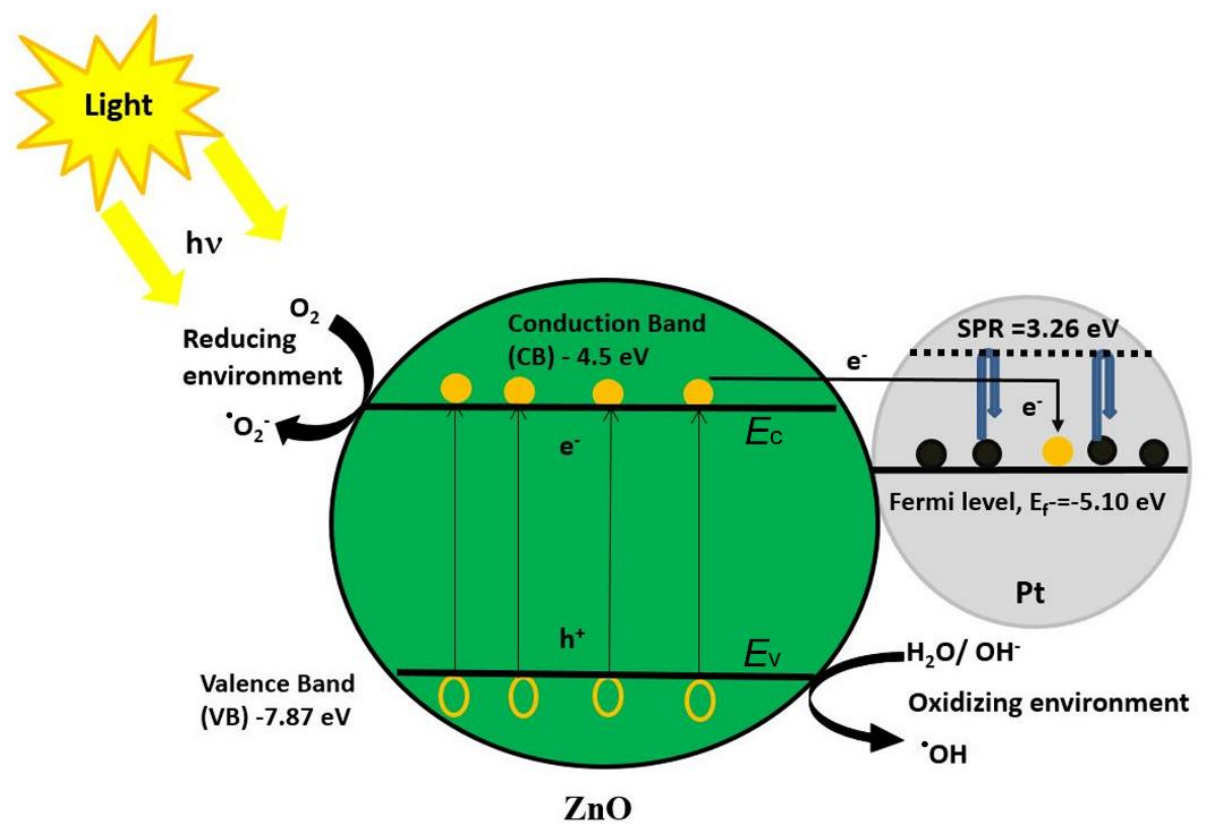

ZnO-Pt (AVS)

Figure 5. The suggested mechanism of enhanced photocatalytic activities with $\mathrm{ZnO}-\mathrm{Pt}$ (energy levels: Absolute vacuum scale (AVS)).

\subsection{Photocatalytic Degradation of Low Density Polyethylene Films}

Photocatalysts were subsequently tested for their ability to break down the most prolific microplastic pollutant in water, low density polyethylene (LDPE). As observed from the FTIR spectra of LDPE fragments, there is a considerable change in its chemical structure before and after visible light photocatalysis with $\mathrm{ZnO}$ and $\mathrm{ZnO}-\mathrm{Pt}$ catalysts (Figure 6). Compared to un-irradiated LDPE fragments, several functional groups can be identified having peaks at $710 \mathrm{~cm}^{-1}$, and $719 \mathrm{~cm}^{-1}$ (medium type rocking deformation of $-\mathrm{CH}_{2}$ ), $2847 \mathrm{~cm}^{-1}, 2915 \mathrm{~cm}^{-1}$ (symmetric and asymmetric strong stretching of $-\mathrm{CH}_{2}$ ), $1462 \mathrm{~cm}^{-1}, 1472 \mathrm{~cm}^{-1}$ (stretching of $-\mathrm{C}=\mathrm{C}$ - bond), and $1377 \mathrm{~cm}^{-1}$ (weak symmetric deformation of $-\mathrm{CH}_{3}$ group), which remain unchanged after the photocatalytic process [33,34]. However, several oxygenated groups like carbonyl, hydroperoxide, peroxides and unsaturated groups within the band from $1700-1760 \mathrm{~cm}^{-1}, 3600-3610 \mathrm{~cm}^{-1}, 1100-1300 \mathrm{~cm}^{-1}$, and $880-920 \mathrm{~cm}^{-1}$ respectively, appear during the photodegradation process which provide evidence of the chemical transformation of LDPE as suggested previously in References [14,35-37]. 


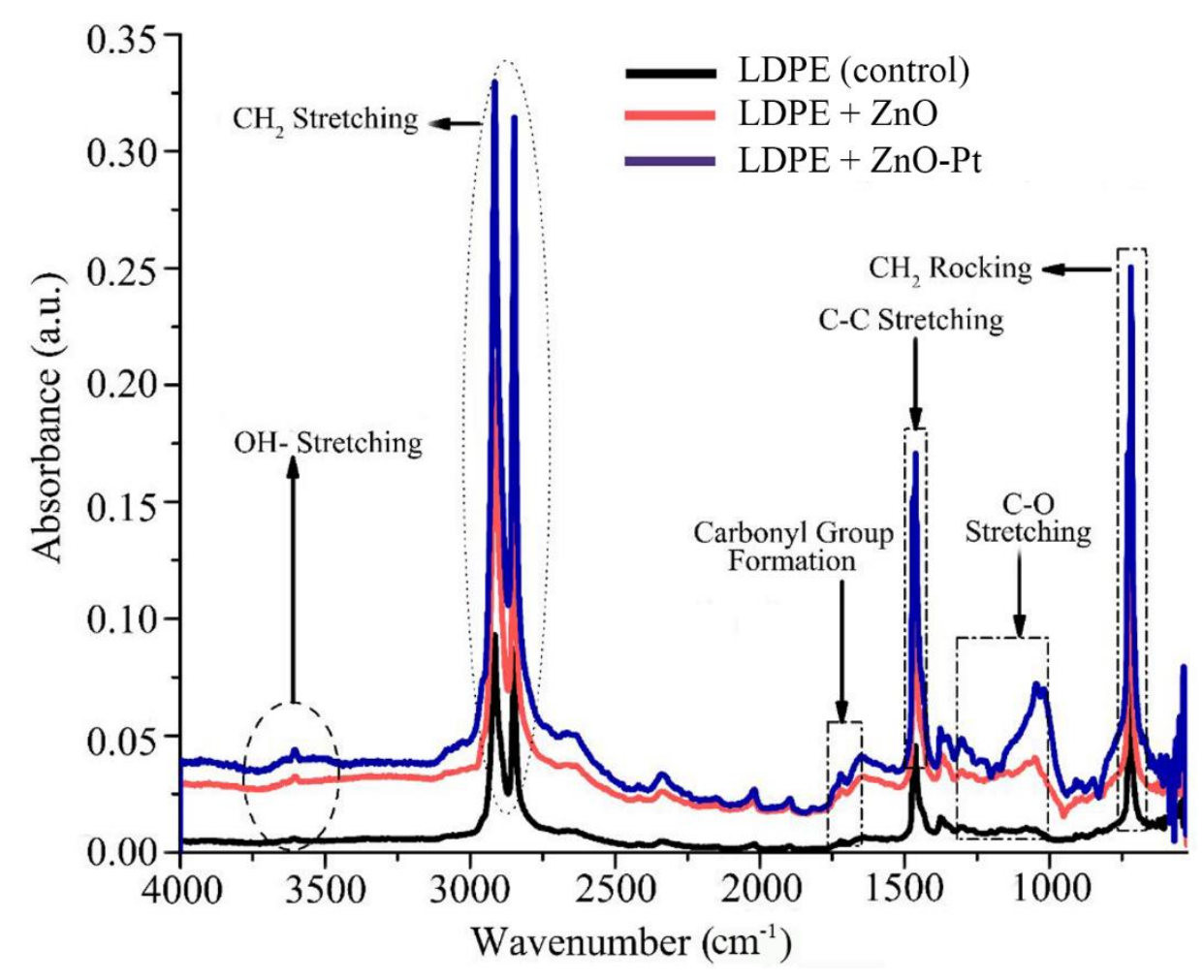

Figure 6. FTIR spectra of low-density polyethylene films before and after irradiation along with $\mathrm{ZnO}$ and $\mathrm{ZnO}-\mathrm{Pt}$ catalysts upon 175 hours exposure under visible light.

Furthermore, carbonyl index (CI) and vinyl index (VI) of photocatalyzed LDPE were calculated to compare the performance of $\mathrm{ZnO}$ and $\mathrm{ZnO}-\mathrm{Pt}$ photocatalysts as these are used for indirect quantification of the degree of degradation [13]. Table 1 presents the carbonyl index and Vinyl index of LDPE films, showing an increment after irradiation. It is clear that the photodegradation efficiency is improved in the presence of $\mathrm{ZnO}$ nanorods with platinum nanoparticles. On average, the carbonyl index and vinyl index increased by 13\% and 15\% respectively, suggesting that the degradation efficiency of $\mathrm{ZnO}-\mathrm{Pt}$ plasmonic photocatalysts is substantially improved compared to the unmodified $\mathrm{ZnO}$ nanorods.

Table 1. Variations in the carbonyl index and vinyl index of photocatalyzed low-density polyethylene films.

\begin{tabular}{ccc}
\hline Catalyst & Carbonyl index (CI) & Vinyl index (VI) \\
\hline LDPE (control) & 0.71 & 0.51 \\
LDPE $+\mathrm{ZnO}$ & 1.38 & 1.12 \\
LDPE $+\mathrm{ZnO}-\mathrm{Pt}$ & 1.49 & 1.35 \\
\hline
\end{tabular}

\subsection{Microstructure Analysis of Non-Irradiated and Irradiated Low Density Polyethylene Films}

Additional visual data was obtained from SEM images (Figure 7a-c), where the morphological changes of the photo-catalytically degraded LDPE films show substantial changes in nanometer scale. The surface of the non-irradiated LDPE was found to be smooth except for a few manufacturing defects and spots [12]. Several wrinkles, cracks and cavities of varying sizes were detected all over the photodegraded films as a result of newly formed oxygenated groups and volatile organic compounds [38]. Deeper cavities and wrinkles were observed on LDPE film when photo-irradiated with $\mathrm{ZnO}-\mathrm{Pt}$ catalyst in comparison with $\mathrm{ZnO}$ upon photodegradation for 175 hours. 

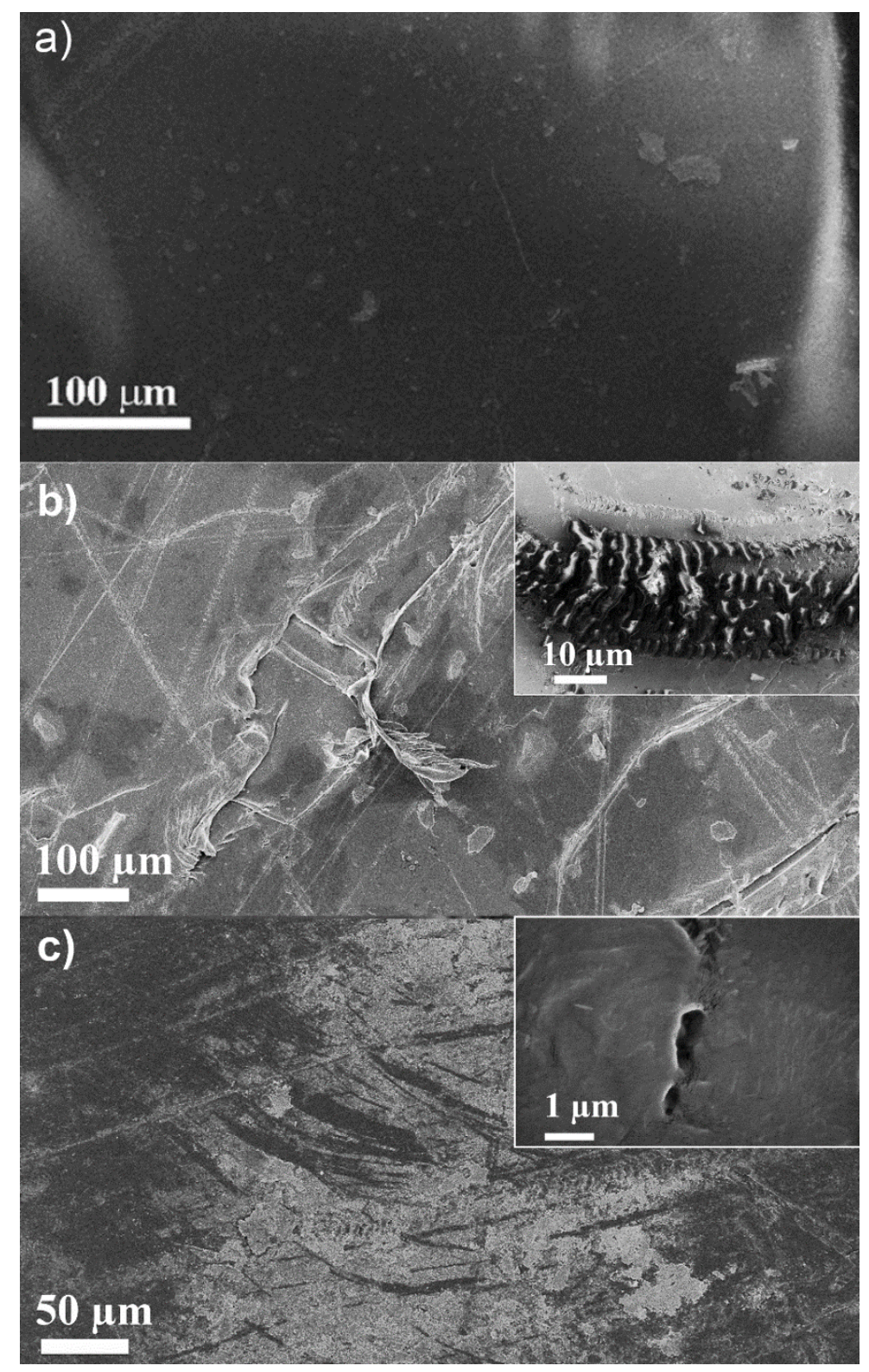

Figure 7. SEM images of low-density polyethylene film after 175 hours of visible light exposure (a) controlled LDPE, (b) $\mathrm{ZnO}$, (c) $\mathrm{ZnO}$-Pt reveal the configuration of cracks, spots and wrinkles; plasmonic catalysts showed better catalytic activities than $\mathrm{ZnO}$ alone.

\section{Materials and Methods}

\subsection{Reagents}

Reagents of zinc acetate dihydrate $\left(\mathrm{Zn}\left(\mathrm{CH}_{3} \mathrm{COO}\right)_{2} \cdot 2 \mathrm{H}_{2} \mathrm{O}\right)$, hexamethylenetetramine $\left(\mathrm{C}_{6} \mathrm{H}_{12} \mathrm{~N}_{4}\right)$, zinc nitrate hexahydrate $\left(\mathrm{Zn}\left(\mathrm{NO}_{3}\right)_{2} \cdot 6 \mathrm{H} 2 \mathrm{O}\right)$, and potassium hexachloroplatinate $\left(\mathrm{K}_{2} \mathrm{PtCl}_{6}\right)$ were purchased from Sigma-Aldrich Chemie $\mathrm{GmbH}$ (Taufkirchen, Munich, Germany) and used without further purification. LDPE film in commercial use, with a thickness of 50 microns, was used to study the photocatalytic degradation studies.

\subsection{Synthesis of Nanostructured Catalysts}

$\mathrm{ZnO}$ nanorods were grown by a hydrothermal process which involved seeding of substrates with $\mathrm{ZnO}$ nanoparticles followed by 5 hours' growth process in growth equimolar solution containing 
$10 \mathrm{mM}$ of hexamethylenetetramine and zinc nitrate hexahydrate at $90^{\circ} \mathrm{C}$. Following the growth of nanorod coatings, the samples were washed extensively with deionized water and then annealed in ambient conditions at $350{ }^{\circ} \mathrm{C}$ for 1 hour prior to further processing [39].

\subsection{Deposition of Platinum Nanoparticles on $\mathrm{ZnO}$ Nanorods}

Pt-deposited $\mathrm{ZnO}$ nanorods ( $\mathrm{ZnO}-\mathrm{Pt}$ ) were prepared using UV-C photoreduction method in which generation of surface defects on the $\mathrm{ZnO}$ nanorods was carried out by exposing the nanorods to a $100 \mathrm{~W}$ vapor mercury UV-C lamp for 30 minutes at a distance of $14 \mathrm{~cm}$ followed by photo mediated crystal growth from $1 \mathrm{mM}$ potassium hexachloroplatinate solution for 10 minutes. After deposition, the substrate was annealed in ambient air at $450^{\circ} \mathrm{C}$ for 1 hour [22,40].

\subsection{Photocatalysis Test Setup}

The performance of designed catalysts was evaluated by following a process defined by the International Organization for Standardization (ISO 10678:2010) which include the degradation of $10 \mu \mathrm{M}$ methylene blue (MB) dye solution ( $3 \mathrm{~mL}$ ) for 90 minutes under light irradiation using $\mathrm{ZnO}$ and $\mathrm{ZnO}-\mathrm{Pt}$ substrates, having dimensions of $2.5 \mathrm{~cm} \times 0.75 \mathrm{~cm}$, as the photocatalysts. Photocatalysis of low-density polyethylene film of size $(1 \mathrm{~cm} \times 1 \mathrm{~cm})$ was carried out for $175 \mathrm{~h}$ in a Petri dish containing synthesized catalysts and deionized water. A $50 \mathrm{~W}$ dichroic halogen lamp in ambient air was used for visible light illumination $(\approx 60-70 \mathrm{klux})$ from a distance of $10 \mathrm{~cm}$ for all photocatalytic degradation studies reported here, as shown in Figure S1 in Supplementary Materials.

\subsection{Characterization Techniques}

Surface topography and morphology of both catalysts and low-density polyethylene were examined by scanning electron microscopy (SEM) (GEMINI ${ }^{\circledR}$ Ultra 55, ZEISS, Oberkochen, Germany ). Energy dispersive X-ray spectroscopy (EDX) was utilized for the identification and determination of the abundance of elements in the designed photocatalysts. Platinum nanoparticle-coated $\mathrm{ZnO}$ nanorods were removed from the substrate by scratching with a sharp blade and drop-casted on copper grids to observe the morphology and crystal structure using high resolution transmission electron microscopy (HR-TEM, JEOL JEM-2100F, Tokyo, Japan).

The optical absorbance of designed catalysts and the degradation kinetics of MB dye were determined using UV-VIS spectrophotometer (LAMBDA-750, PerkinElmer, Waltham, MA, USA). Photoluminescence (PL) spectrophotometer (model LS 55, PerkinElmer, Waltham, MA, USA) was used for the assessment of intrinsic and UV-induced defect density for $\mathrm{ZnO}$ and $\mathrm{ZnO}-\mathrm{Pt}$ samples. Emission spectra were obtained using an excitation wavelength of $320 \mathrm{~nm}$ [41].

Fourier transformation infra-red (FTIR) spectra of low-density polyethylene film was obtained using FTIR spectrometer (Nicolet ${ }^{\mathrm{TM}}$ iS10, Thermo Fisher Scientific, Waltham, MA, USA) to observe the variations of functional groups of polymer during photocatalytic degradation. Changes in the carbonyl index (CI) determined by the ratio of the area under the absorbance of $1710 \mathrm{~cm}^{-1}$ to the area under the reference peak at $1380 \mathrm{~cm}^{-1}$ and the Vinyl index (VI) which is the ratio of area under the absorbance of $909 \mathrm{~cm}^{-1}$ to the area under the reference peak at $1380 \mathrm{~cm}^{-1}$ were monitored $[13,14]$.

\section{Conclusions}

Enhancement of visible light absorption, due to plasmon absorption in the platinum nanoparticles, along with the diffusion of photogenerated electrons into platinum from the $\mathrm{ZnO}$ nanorod interfaces reduces electron-hole recombination. This leads to more than $15 \%$ enhancement of photocatalytic performance with visible light irradiation, due to the combined effects enumerated above of the plasmonic catalyst. The photocatalytic activity for the degradation of organic matters (using methylene blue dye as a contaminant) was found to occur primarily, due to the contribution of superoxides and hydroxyl radicals that form during the photocatalysis. The plasmonic photocatalyst ( $\mathrm{ZnO}-\mathrm{Pt}$ ) was found to degrade microplastic pollutants like residual LDPE films in water effectively. Formation of 
oxygenated groups like hydro-peroxides, peroxides, and unsaturated groups resulted in wrinkles, cracks and holes ensure the photocatalytic degradation of LDPE films. Modified ZnO-Pt catalysts showed ca. 13\% higher potential for oxidation of LDPE film compared to the as-grown $\mathrm{ZnO}$ nanorods. Thus, modification of $\mathrm{ZnO}$ with plasmonic metal could be a viable way for expediting the oxidation of microplastic pollutants in water using sunlight.

Supplementary Materials: The following are available online at http://www.mdpi.com/2073-4344/9/10/819/s1, Figure S1: Experimental setup for photocatalytic degradation of LDPE film, Figure S2: X-ray dispersive spectroscopy (EDX) result showing the relative elemental composition of $\mathrm{ZnO}-\mathrm{Pt}$ catalyst.

Author Contributions: Conceptualization, J.D.; Formal analysis, T.S.T., F.Y. and K.L.K.; Funding acquisition, J.D.; Investigation, T.S.T. and F.Y.; Methodology, T.S.T. and J.D.; Supervision, J.D.; Writing—original draft, T.S.T., F.Y. and K.L.K.; Writing-review and editing, J.D.

Funding: This research was funded by the European Commission through the EU research and innovation funding programme Horizon 2020, grant number 774586 (CLAIM-Cleaning Litter by developing and Applying Innovative Methods in european seas).

Acknowledgments: The publication of this article was funded by KTH Royal Institute of Technology.

Conflicts of Interest: The authors declare no conflict of interest.

\section{References}

1. Barnes, D.K.A.; Galgani, F.; Thompson, R.C.; Barlaz, M. Accumulation and fragmentation of plastic debris in global environments. Philos. Trans. R. Soc. London Ser. B 2009, 364, 1985-1998. [CrossRef] [PubMed]

2. Bergmann, M.; Gutow, L.; Klages, M. Marine Anthropogenic Litter; Springer International Publishing: Cham, Switzerland, 2015.

3. Wu, W.-M.; Yang, J.; Criddle, C.S. Microplastics pollution and reduction strategies. Front. Environ. Sci. Eng. 2016, 11, 6. [CrossRef]

4. Talvitie, J.; Heinonen, M.; Pääkkönen, J.P.; Vahtera, E.; Mikola, A.; Setälä, O.; Vahala, R. Do wastewater treatment plants act as a potential point source of microplastics? Preliminary study in the coastal Gulf of Finland, Baltic Sea. Water Sci. Technol. 2015, 72, 1495-1504. [CrossRef] [PubMed]

5. Auta, H.S.; Emenike, C.U.; Fauziah, S.H. Distribution and importance of microplastics in the marine environment: A review of the sources, fate, effects, and potential solutions. Environ. Int. 2017, 102, 165-176. [CrossRef] [PubMed]

6. Talvitie, J.; Mikola, A.; Koistinen, A.; Setälä, O. Solutions to microplastic pollution-Removal of microplastics from wastewater effluent with advanced wastewater treatment technologies. Water Res. 2017, 123, 401-407. [CrossRef] [PubMed]

7. Westphalen, H.; Abdelrasoul, A. Challenges and treatment of microplastics in water. In Water Challenges of an Urbanizing World; Glavan, M., Ed.; IntechOpen: London, UK, 2017.

8. Singh, B.; Sharma, N. Mechanistic implications of plastic degradation. Polym. Degrad. Stab. 2008, 93, 561-584. [CrossRef]

9. Klein, S.; Dimzon, I.K.; Eubeler, J.; Knepper, T.P. Analysis, occurrence, and degradation of microplastics in the aqueous environment. In Freshwater Microplastics. The Handbook of Environmental Chemistry; Wagner, M., Lambert, S., Eds.; Springer: Cham, Switzerland, 2018; Volume 58, pp. 51-57.

10. Zhou, D.; Chen, L.; Li, J.; Wu, F. Transition metal catalyzed sulfite auto-oxidation systems for oxidative decontamination in waters: A state-of-the-art minireview. Chem. Eng. J. 2018, 346, 726-738. [CrossRef]

11. Kang, J.; Zhou, L.; Duan, X.; Sun, H.; Ao, Z.; Wang, S. Degradation of cosmetic microplastics via functionalized carbon nanosprings. Matter 2019, 1, 745-758. [CrossRef]

12. Yousif, E.; Haddad, R. Photodegradation and photostabilization of polymers, especially polystyrene: Review. SpringerPlus 2013, 2, 398. [CrossRef] [PubMed]

13. Ali, S.S.; Qazi, I.A.; Arshad, M.; Khan, Z.; Voice, T.C.; Mehmood, C.T. Photocatalytic degradation of low density polyethylene (LDPE) films using titania nanotubes. Environ. Nanotechnol. Monit. Manag. 2016, 5, 44-53. [CrossRef]

14. Tofa, T.S.; Kunjali, K.L.; Paul, S.; Dutta, J. Visible light photocatalytic degradation of microplastic residues with zinc oxide nanorods. Environ. Chem. Lett. 2019. [CrossRef] 
15. Ariza-Tarazona, M.C.; Villarreal-Chiu, J.F.; Barbieri, V.; Siligardi, C.; Cedillo-González, E.I. New strategy for microplastic degradation: Green photocatalysis using a protein-based porous $\mathrm{N}-\mathrm{TiO}_{2}$ semiconductor. Ceram. Int. 2019, 45, 9618-9624. [CrossRef]

16. Li, S.; Xu, S.; He, L.; Xu, F.; Wang, Y.; Zhang, L. Photocatalytic degradation of polyethylene plastic with polypyrrole/ $\mathrm{TiO}_{2}$ nanocomposite as photocatalyst. Polym. Plast. Technol. Eng. 2010, 49, 400-406. [CrossRef]

17. Laxman, K.; Al Rashdi, M.; Al Sabahi, J.; Al Abri, M.; Dutta, J. Supported versus colloidal zinc oxide for advanced oxidation processes. Appl. Surf. Sci. 2017, 411, 285-290. [CrossRef]

18. Qi, K.; Cheng, B.; Yu, J.; Ho, W. Review on the improvement of the photocatalytic and antibacterial activities of ZnO. J. Alloys Compd. 2017, 727, 792-820. [CrossRef]

19. Bora, T.; Dutta, J. Plasmonic photocatalyst design: Metal-semiconductor junction affecting photocatalytic efficiency. J. Nanosci. Nanotechnol. 2019, 19, 383-388. [CrossRef] [PubMed]

20. Lin, J.M.; Lin, H.Y.; Cheng, C.L.; Chen, Y.F. Giant enhancement of bandgap emission of ZnO nanorods by platinum nanoparticles. Nanotechnology 2006, 17, 4391-4394. [CrossRef]

21. Wang, P.; Huang, B.; Dai, Y.; Whangbo, M.H. Plasmonic photocatalysts: Harvesting visible light with noble metal nanoparticles. Phys. Chem. Chem. Phys. 2012, 14, 9813-9825. [CrossRef] [PubMed]

22. Al-Alawi, R.; Laxman, K.; Dastgir, S.; Dutta, J. Role of bonding mechanisms during transfer hydrogenation reaction on heterogeneous catalysts of platinum nanoparticles supported on zinc oxide nanorods. Appl. Surf. Sci. 2016, 377, 200-206. [CrossRef]

23. Bora, T.; Zoepfl, D.; Dutta, J. Importance of plasmonic heating on visible light driven photocatalysis of gold nanoparticle decorated zinc oxide nanorods. Sci. Rep. 2016, 6, 26913. [CrossRef] [PubMed]

24. Chichagov, A.; Belonozhko, A.; Lopatin, A.; Dokina, T.; Samokhvalova, O.; Ushakovskaya, T.; Shilova, Z. Information computing system from structural data on minerals (Mincryst). Kristallografiya 1990, 35, 610-616.

25. Sun, F.; Qiao, X.; Tan, F.; Wang, W.; Qiu, X. One-step microwave synthesis of Ag/ZnO nanocomposites with enhanced photocatalytic performance. J. Mater. Sci. Mater. Electron. 2012, 47, 7262-7268. [CrossRef]

26. Yang, T.; Wang, M.; Duan, C.; Hu, X.; Huang, L.; Peng, J.; Huang, F.; Gong, X. Inverted polymer solar cells with $8.4 \%$ efficiency by conjugated polyelectrolyte. Energy Environ. Sci. 2012, 5, 8208-8214. [CrossRef]

27. Zhang, N.; Tang, W.; Wang, P.; Zhang, X.; Zhao, Z. In situ enhancement of NBE emission of Au-ZnO composite nanowires by SPR. Cryst. Eng. Comm. 2013, 3301-3304. [CrossRef]

28. Anandan, S.; Vinu, A.; Sheeja Lovely, K.L.P.; Gokulakrishnan, N.; Srinivasu, P.; Mori, T.; Murugesan, V.; Sivamurugan, V.; Ariga, K. Photocatalytic activity of La-doped $\mathrm{ZnO}$ for the degradation of monocrotophos in aqueous suspension. J. Mol. Catal. A Chem. 2007, 266, 149-157. [CrossRef]

29. Yu, C.; Yang, K.; Xie, Y.; Fan, Q.; Yu, J.C.; Shu, Q.; Wang, C. Novel hollow Pt-ZnO nanocomposite microspheres with hierarchical structure and enhanced photocatalytic activity and stability. Nanoscale 2013, 5, 2142. [CrossRef] [PubMed]

30. Baruah, S.; Mahmood, M.A.; Myint, M.T.Z.; Bora, T.; Dutta, J. Enhanced visible light photocatalysis through fast crystallization of zinc oxide nanorods. Beilstein J. Nanotechnol. 2010, 1, 14-20. [CrossRef] [PubMed]

31. Flyunt, R.; Knolle, W.; Kahnt, A.; Halbig, C.E.; Lotnyk, A.; Häupl, T.; Prager, A.; Eigler, S.; Abel, B. High quality reduced graphene oxide flakes by fast kinetically controlled and clean indirect UV-induced radical reduction. Nanoscale 2016, 8, 7572-7579. [CrossRef] [PubMed]

32. Vinoth, R.; Babu, S.G.; Ramachandran, R.; Neppolian, B. Bismuth oxyiodide incorporated reduced graphene oxide nanocomposite material as an efficient photocatalyst for visible light assisted degradation of organic pollutants. Appl. Surf. Sci. 2017, 418, 163-170. [CrossRef]

33. Gulmine, J.V.; Janissek, P.R.; Heise, H.M.; Akcelrud, L. Polyethylene characterization by FTIR. Polym. Test. 2002, 21, 557-563. [CrossRef]

34. Mouallif, I.; Latrach, A.; Benali, C.M.H.; Barbe, N. FTIR study of HDPE structural changes, moisture absorption and mechanical properties variation when exposed to sulphuric acid aging in various temperatures. In 20ÈME Congrès Français de Mécanique, AFM; Maison de la Mécanique: Besançon, France, 2011; pp. 2011-25044.

35. Luongo, J.P. Infrared study of oxygenated groups formed in polyethylene during oxidation. J. Polym. Sci. 1960, 42, 139-150. [CrossRef]

36. Qin, H.; Zhao, C.; Zhang, S.; Chen, G.; Yang, M. Photo-oxidative degradation of polyethylene/montmorillonite nanocomposite. Polym. Degrad. Stab. 2003, 81, 497-500. [CrossRef] 
37. Gardette, M.; Perthue, A.; Gardette, J.L.; Janecska, T.; Földes, E.; Pukánszky, B.; Therias, S. Photo- and thermal-oxidation of polyethylene: Comparison of mechanisms and influence of unsaturation content. Polym. Degrad. Stab. 2013, 98, 2383-2390. [CrossRef]

38. Shang, J.; Chai, M.; Zhu, Y. Photocatalytic degradation of polystyrene plastic under fluorescent light. Environ. Sci. Technol. 2003, 37, 4494-4499. [CrossRef]

39. Baruah, S.; Dutta, J. Hydrothermal growth of ZnO nanostructures. Sci. Technol. Adv. Mater. 2009, $10,013001$. [CrossRef] [PubMed]

40. Myint, M.T.Z.; Kumar, N.S.; Hornyak, G.L.; Dutta, J. Hydrophobic/hydrophilic switching on zinc oxide micro-textured surface. Appl. Surf. Sci. 2013, 264, 344-348. [CrossRef]

41. Baral, A.; Khanuja, M.; Islam, S.S.; Sharma, R.; Mehta, B.R. Identification and origin of visible transitions in one dimensional (1D) ZnO nanostructures: Excitation wavelength and morphology dependence study. J. Lumin. 2017, 183, 383-390. [CrossRef]

(C) 2019 by the authors. Licensee MDPI, Basel, Switzerland. This article is an open access article distributed under the terms and conditions of the Creative Commons Attribution (CC BY) license (http://creativecommons.org/licenses/by/4.0/). 